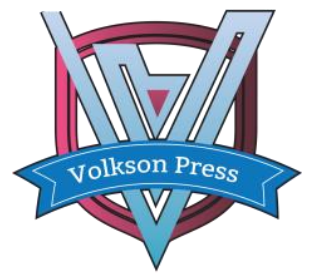

Contents List available at VOLKSON PRESS

Economics \& Management Innovations(EMI)

DOI : http://doi.org/10.26480/icemi.01.2017.217.219

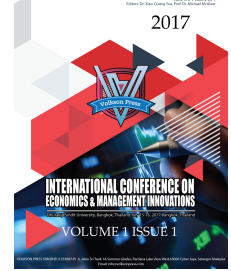

\title{
Can the Balance of Management Control Improve Performance?
}

\author{
Liang $\mathrm{Wu}^{1}$, Hongjiang $\mathrm{Lv}^{2, *}$
}

${ }^{1}$ School of Economics and Management, Southeast University, Nanjing, China

${ }^{2}$ School of Economics and Management, Southeast University, Nanjing, China *Email: luj602@163.com

This is an open access article distributed under the Creative Commons Attribution License, which permits unrestricted use, distribution, and reproduction in any medium, provided the original work is properly cited.

\section{ARTICLE DETAILS}

\section{Article History:}

Received 02 october 2017

Accepted 06 october 2017

Available online 11 october 2017

Keywords:

Consistency;

control;

performance

\section{ABSTRACT}

The balance of management control has become more important with the advent of the new control era, but mainstream researches often separate to discuss it. The study analyzes the influence of consistency of management control on performance and finds that consistency between process and social control has a positively impact on organizational performance, consistency between process and cultural control has a positively impact on organizational performance, consistency between output and social control has a positively impact on organizational performance, and consistency between output and cultural control has an inverted U-shaped impact on organizational performance. The findings have important implications for the study of formal and informal management control of Chinese enterprises.

\section{Introduction}

Research suggests that exploiting of formal and informal management control simultaneously can contribute to organizational performance (Ouchi, 1979; Jaworski, 1988; Voss and Brettel, 2014; Guenzi et al., 2014). However, although most studies have been aware of this, research on consistency in theory and practice has largely ignored how to measure and exert them special for the influence of organizational performance, and the studies of formal and informal controls are often separated (Jaworski et al., 1993). In the present paper, we fundamentally believe that both informal and formal management control need to be examined together in terms of their consistency, and two sets of control elements act in tandem has implications for organizational performance.

Based on the special types of management control, we will build on consistency between formal and informal management control, and separately check the influence of them on organizational performance. In a survey of 166 employees in 7 Chinese firms, our findings extend the understanding of how the consistency between formal and informal management control function as complements of the study in organizational control theory.

\section{Theory and Hypotheses}

\subsection{Formal and Informal Management Control}

So far, the most researches have always followed the basic management control framework of Jaworski et al. (1993). In their article, formal control is defined as the written, management-initiated mechanisms that influence the organizational performance that employees will behave in ways that support the stated working objectives. Two typically formal controls in organization are process and output control. Informal control is unwritten, typically worker-initiated mechanisms that influence the behavior of individuals or groups, two typically informal controls in organization are social control and cultural control. Therefore, in the present paper, we will use the basic management control types of Jaworski et al. (1993).

\subsection{Consistency between Process and Social Control}

Process control refers to the formal mechanisms designed to influence employees' behavior to achieve desired ends (Jaworski et al., 1993). Social control refer to the informal mechanisms designed to staffs engage in high levels of collegial interaction, discussion, team working, and informal evaluations of one's work (Ouchi,1979). When process and social control have a higher consistency, it will be good for organizational performance. This is because control employees' behavior needs more skills in terms of process control, hence there must take lots of conflicts between managers and employees, and necessary social interactions are useful to increase the intimacy and alleviate contradiction between them. Hence, we therefore posit:

Hypothesis 1: Consistency between process and social control is positively associated with organizational performance.

\subsection{Consistency between Process and Cultural Control}

Cultural control refers to the broader values and normative patterns that guide worker behavior within the whole organization (Jaworski, 1988). Voss and Brettel (2014) points out that managers require culture as an informal control mean to improve formal control effectively especially when their power position becomes impaired. Therefore, when cultural control and process control have a higher consistency, undoubtedly, it will help staffs clear their target and resolving their stress. But for a long run, organization needs to change its values and norms to adapt the external environment for keeping sustainable competitive advantage. As consistency between process and cultural control become stronger, organization will be lock-in. Hence, we therefore posit:

Hypothesis 2: Consistency between process and cultural control has an inverted U-shaped relationship with organizational performance.

\subsection{Consistency between Output and Social Control}

Output control refers to the formal mechanisms designed to monitor or evaluate the results of staff's behaviors relative to some standard of performance (Guenzi et al., 2014). When output and social control have a higher consistency, it will be good for organizational performance. Specifically, first, through collegial interaction, team working and internalizing the prevailing norms of social control, it may eliminate one's stress and decrease pressure of the output control. Second, on the contrary, output control can also correct some social deviations, such as when a staff is not worker-oriented, others can work to ensure that the individual's behavior gets back on work through subtle forms such as humor, kidding, or hinting. Hence, we therefore posit: 
Hypothesis 3: Consistency between output and social control is positively associated with organizational performance.

\subsection{Consistency between Output and Cultural Control}

As the same logic of consistency of process and cultural control mentioned before, we think the consistency between output and cultural control also has an inverted U-shaped relationship to organizational performance. In the short time, cultural control can help to monitor or evaluate the results of staff's behaviors (Voss and Brettel, 2014). But for a long run, the culture will be lock-in, undoubtedly, it will deter organization from adapting the change of external environment. Hence, we therefore posit:

Hypothesis 4: Consistency between output and cultural control has an inverted U-shaped relationship with organizational performance.

\section{Methods}

\subsection{Sample and Data Collection}

In order to test the proposed relationships, we identified a company sample ( 7 firms) through friends and colleagues located in two provinces including Jiangsu and Shanxi in China. 247 questionnaires were issued, 166 usable surveys were obtained, a response rate of $67.2 \%$.

\subsection{Measurement and Validation of Constructs}

Dependent Variable: Organizational performance $(\alpha=0.865)$ is measured using items for overall profitability, return on investment, market share, and overall commercial success as measured relative to goals. These organizational performance measures have been frequently used in previous literature (Tang et al., 2015).

Independent Variables: We used a two-step approach to measure the consistency between formal and informal management control. First, Jaworski et al. (1993) four reflective scales were used to measure formal control and informal control, which respectively are process control $(\alpha=0.865)$, output control $(\alpha=0.792)$, social control $(\alpha=0.913)$ and cultural control $(\alpha=0.884)$. Second, to develop a measure for consistency of formal and informal control, we followed the procedures recommended Jansen et al. (2009). Using multiplying, adding and subtracting to explore the consistency between formal and informal management control. The result showed that for the consistency between process and social control, the multiplicative model proved to be superior; for the consistency between process and cultural control and the consistency between output and social control, the multiplicative model also proved to be superior; for the consistency between output and cultural control, the additive model proved to be superior.

Control Variables: In order to control for possible alternative explanations, several control variables were measured including firm type, firm size, gender, working time, position and education. These are all the important factors to organizational performance. Except, ambidexterity of exploratory and exploitative is more important to organizational performance. We used the same way of control consistency to calculate it based an eight-item measure from He and Wong (2004). The result showed that the additive model proved to be superior.

\section{Analysis and Results}

The Table of descriptive statistics and correlation matrix (ellipsis) find that all the consistency variables between formal and informal management control have a high correlation, so hierarchical regression analysis was used to test the hypotheses. Tables 1 are hierarchical regression results of formal and informal management control. In model 2 , consistency between process and social control has a positive and significant impact on organizational performance $(\beta=0.00867, p<0.05)$. H1 is supported. In model 3 and model 4 , the result only shows that consistency between process and cultural control has a positively impact on organizational performance $(\beta=0.00908, p<0.05)$, so $H 2$ can't be supported.

Table 1. Hierarchical regression results

\begin{tabular}{|c|c|c|c|c|c|c|c|}
\hline $\begin{array}{l}\text { Variab } \\
\text { les }\end{array}$ & $\begin{array}{l}\text { Mdoe } \\
1\end{array}$ & Mdoe2 & Mode3 & Mode4 & $\begin{array}{l}\text { Mode } \\
5\end{array}$ & $\begin{array}{l}\text { Mode } \\
6\end{array}$ & Mode7 \\
\hline Consta & \multirow{3}{*}{$\begin{array}{l}3.006 \\
* * * \\
(7.48 \\
)\end{array}$} & $2.865^{* *}$ & \multirow{3}{*}{$\begin{array}{l}2.926^{* *} \\
(7.37)\end{array}$} & \multirow{3}{*}{$\begin{array}{l}2.848^{* *} \\
(6.91)\end{array}$} & \multirow{3}{*}{$\begin{array}{l}2.800^{*} \\
* * \\
(7.04)\end{array}$} & \multirow{3}{*}{$\begin{array}{l}2.771 \\
* * * \\
(6.78)\end{array}$} & \multirow{3}{*}{$\begin{array}{l}2.250^{* *} \\
(4.84)\end{array}$} \\
\hline nt & & $(7.12)$ & & & & & \\
\hline (1) & & 0.0086 & & & & & \\
\hline
\end{tabular}

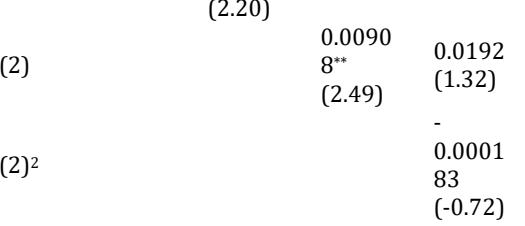

$1^{* *}$ (2.37)

$0.134^{* *}$ $5^{* * *}$

$(4)^{2}$

Table
1.con

0.0037 $1^{* *}$

0.151

(6)

(-

3.12)

0.025

9

(0.55

(7)

0.034

(7)

(8)

$0.45)$ 0.056

(9)

(9)

\begin{tabular}{|c|c|c|c|c|c|c|c|}
\hline \multirow{3}{*}{ (10) } & & & & & & & \\
\hline & \multirow{2}{*}{$\begin{array}{l}0.095 \\
1 \\
(- \\
1.57)\end{array}$} & 0.0806 & 0.0787 & \multirow{2}{*}{$\begin{array}{l}0.0839 \\
(-1.38)\end{array}$} & \multirow{2}{*}{$\begin{array}{l}0.077 \\
7 \\
(- \\
1.31)\end{array}$} & $\begin{array}{l}0.087 \\
8\end{array}$ & 0.0831 \\
\hline & & $(-1.34)$ & $(-1.31)$ & & & $(--)$ & $(-1.40)$ \\
\hline \multirow{2}{*}{ (11) } & 0.237 & $0.228^{* *}$ & $0.221^{* *}$ & $0.220^{* *}$ & $0.226^{*}$ & 0.223 & $0.217^{* *}$ \\
\hline & (9.39 & $(9.03)$ & $(8.60)$ & $(8.56)$ & $(9.07)$ & (8.72) & $(8.56)$ \\
\hline $\begin{array}{l}\text { Adjust } \\
\text { ed } R^{2}\end{array}$ & 0.442 & 0.456 & 0.460 & 0.458 & 0.470 & 0.458 & 0.472 \\
\hline F & 19.69 & $18.26^{* *}$ & $18.58^{* *}$ & $16.52^{* * *}$ & $19.28^{*}$ & 18.44 & $17.38^{* *}$ \\
\hline
\end{tabular}

Note: ${ }^{*} \mathrm{p}<0.10,{ }^{* *} \mathrm{p}<0.05,{ }^{* * *} \mathrm{p}<0.01$. (1) Consistency between process and social control; (2) Consistency between process and cultural control; (3) Consistency between output and social control; (4) Consistency between output and cultural control (5) Firm types; (6) Firm size; (7) Gender; (8) Working time; (9) Position; (10) Education; (11) Ambidexterity.

In model 5 , consistency between output and social control has a positive and significant impact on organizational performance $(\beta=0.0115, p<0.01)$. H3 is supported. In model 6 and model 7 , the result shows that squared consistency between output and cultural control has a negative and significant impact on organizational performance $(\beta=-0.00371, p<0.05)$. Therefore, $\mathrm{H} 4$ is supported strongly.

\section{Conclusions}

The results show that consistency between process and social control has a positively impact on organizational performance, consistency between process and cultural control has a positively impact on organizational performance, consistency between output and social control has a positively impact on organizational performance, consistency between output and cultural control has an inverted U-shaped impact on organizational performance. The findings have important implications for the study of formal and informal management control of Chinese enterprises.

\section{References}

[1] Z. He, and P. Wong: Exploration vs. Exploitation: An Empirical Test of the Ambidexterity Hypothesis. Organization Science, vol.15 (2004), pp.481-494. 
[2] B. Jaworski: Toward a Theory of Marketing Control: Environmental Context, Control Types, and Consequences. Journal of Marketing, vol.52, no.3 (1988), pp.23-39.

[3] B. Jaworski, V. Stathakopoulos, and H. S. Krishnan: Control Combinations in Marketing: Conceptual Framework and Empirical Evidence. Journal of Marketing, vol.57, no.1 (1993), pp.57-69.

[4] J. J. P. Jansen, M. P. Tempelaar, F. A. J.van den Bosch, and H. W. Volberda: Structural Differentiation and Ambidexterity: The Mediating Role of Integration Mechanisms. Organization Science, vol.20, no.4 (2009), pp.797-811.
[5] F. Tang, J. Mu, and E. Thomas: Who Knows What in NPD Teams: Communication Context, Mode, and Task Contingencies. Journal of Product Innovation Management, vol.32, no.3 (2015), pp. 404-423.

[6] W. G. Ouchi: A Conceptual Framework for the Design of Organizational Control Mechanisms. Management Science, vol.25, no.9 (1979), pp.833848.

[7] U. Voss, and M. Brettel: The Effectiveness of Management Control in Small Firms: Perspectives from Resource Dependence Theory. Journal of Small Business Management, vol.52, no.3 (2014), pp.569-587.

[8] P. Guenzi, A. Baldauf, and N.G. Panagopoulos: The Influence of Formal and Informal Sales Controls on Customer-Directed Selling Behaviors and Sales Unit Effectiveness. Industrial Marketing Management, vol.43, no.5 (2014), pp.786-800. 